\title{
O desconhecido da Sorbonne: sobre os historiadores e "os anos" 68
}

\author{
The unknown of Sorbonne: \\ on historians and the "68's"
}

Philippe Artières

No começo de Michel Foucault tel que je l'imagine, o escritor Maurice Blanchot conta que cruzou com o filósofo em maio de 1968 no pátio da Sorbonne: "Nunca tive relações pessoais com Michel Foucault. Nunca me encontrei com ele, a não ser uma vez no pátio da Sorbonne durante os événements de maio de $68,[. .$.$] quando lhe dirigi algumas palavras sem que ele soubesse quem eu era$ (não importa o que digam os detratores de maio, foi um belo momento aquele, em que cada um podia falar com o outro de modo anônimo, impessoal, homem entre os homens aceito sem outra justificativa que não a de ser outro homem)" (Blanchot, 1986). Assim também, Jules Vuillemin, no necrológio que dedicou a

Philippe Artières é doutor em história, pesquisador do Centre National de la Recherche Scientifique (CNRS) e diretor do Centre Michel Foucault em Paris (ph.artieres@wanadoo.fr).

Artigo recebido em maio e aprovado para publicação em junho de 2008.

Tradução de Dora Rocha.

Estudos Históricos, Rio de Janeiro, vol. 21, nº 42, julho-dezembro de 2008, p. 133-144. 
Foucault no Collège de France, evoca essa mesma cena: "Seu encontro com a história, em 68, ele próprio o descreveu, comparando-se a um homem dentro de um escafandro no fundo do mar, que a tempestade de repente deposita na costa. Uma multidão o esperava. Ela ouviu a voz surgida do abismo. A voz falava uma língua que a multidão entendia e a mensagem era bem-vinda. Pois era uma mensagem de felicidade, como a dos sábios antigos, quando a verdade ainda era o outro nome do poder e do desejo".

Ora, tenho a impressão, de acordo com seus biógrafos David Macey e Didier Eribon, e com o depoimento de seu companheiro Daniel Defert, que Foucault naquele momento não estava em Paris, e sim na Tunísia, apoiando outras lutas, outros estudantes, rebelados contra o regime repressor de Bourguiba. ${ }^{1}$

Esse equívoco, ou no mínimo essa incerteza biográfica, muitas vezes me perturbou, me deixou em dúvida - Sartre podia ser visto nos boulevards, mas Foucault? Para ser mais preciso, essa hesitação sempre me seduziu profundamente. Que afinal não se saiba com certeza se o autor da História da loucura pisava o chão de Paris naquele momento me agrada muito, pois hoje existiria como que uma evidência de que ele estava ali, no Quartier, como se dizia então, no meio dos rebeldes, de tal forma ele encarnou aqueles "anos" 68. Por isso mesmo é possível entender por que, retrospectivamente, algumas pessoas, a começar por Maurice Blanchot, acham que cruzaram com ele... O próprio discurso do filósofo as encoraja a isso. Em 1975, por exemplo, numa entrevista a Jacques Chancel, Foucault declarou que 68 significou a invasão de um novo tipo de saber do qual ele foi sem querer um dos símbolos, e lembrou Nietzsche para se autodesignar um "fouilleur de bas-fonds", um explorador de sarjetas que virou professor do Collège de France graças a maio de 68. Maurice Clavel, seu amigo, não dizia coisa muito diferente em Ce que je crois, também de 1975: "Quando desembarquei em Paris, em 3 de maio, comprei os jornais na Gare de Lyon e, vendo as manchetes sobre o primeiro enfrentamento com os estudantes, disse à minha mulher, com uma calma talvez estranha: pronto, chegamos lá. Onde? - ela me perguntou... Em pleno Foucault. Afinal, As palavras e as coisas não eram o formidável prenúncio do deslocamento geológico da nossa cultura humanista que iria ocorrer em maio de 1968 ?"

Que Foucault pudesse estar longe em maio, pudesse estar pisando não os paralelepípedos das ruas de Paris, mas as areias da África do Norte, é algo que me encanta. No livro 68: une histoire collective [1962-1981], que coordenei junto com Michelle Zancarini-Fournel, esta é a primeira afirmação: a cena da história de 68 não se localiza apenas em Paris, e é preciso romper com um certo folclore no qual ela foi rapidamente aprisionada, um pequeno teatro com seus cenários, seus grandes momentos e seus protagonistas, que a cada aniversário nós solidifica- 
mos um pouco mais em suas funções. É preciso, ainda, ir além da iconografia, pois, se 68 produziu uma inundação de discursos, foi também objeto de um número incalculável de representações. A fotografia desempenhou um papel central nessa construção iconográfica, e ao longo do tempo 68 tornou-se um álbum que expõe uma estética. Quantos livros de imagens foram lançados, nestes últimos 40 anos, encobrindo o discurso histórico e neutralizando as lógicas coletivas que estavam em ação no movimento! A fotografia produziu uma representação fragmentada, focalizada no detalhe e na anedota, em que a busca do contexto desapareceu. ${ }^{2}$ Construir a história de 68 passa também, portanto, por uma problematização dessas imagens, não apenas como fonte, mas como objeto.

Para sairmos em busca desses outros lugares da história de 68, e nos livrarmos de uma iconografia folclórica que associa Dany Le Rouge, forças policiais e barricadas do Quartier Latin, fomos beneficiados pelo alargamento da noção de "fonte", que passou a incluir sobretudo os arquivos pessoais: a carta, o diário, a autobiografia, mobilizados não apenas como ilustrações, mas como objetos inscritos na história. Alguns arquivos desprezados, como as séries judiciárias, também foram revalorizados pelos historiadores, aos quais se abriram ainda outros materiais, como os arquivos das televisões e das rádios. Resultaram daí um questionamento mais sério do status de fonte e o desenvolvimento de uma história dos arquivos (de sua produção à sua consulta).

As pesquisas que compõem 68: une histoire collective baseiam-se em arquivos até então inexplorados. A constituição, ao longo dos últimos 15 anos, de fundos específicos, as coletas de arquivos privados, a abertura de arquivos públi$\cos$, modificaram a própria possibilidade de construir a história desse período. Ao apelo feito em 1989 pelos fundadores da associação "Memórias de 68"3 - que se atribuíram a tarefa de conservar o maior número de documentos sobre os movimentos e as organizações da época - seguiu-se o exame de centenas de maços de papéis: arquivos de organizações políticas, fichas de consulta médica, papéis de advogados, arquivos do Serviço de Informações. As bibliotecas, e sobretudo a Biblioteca de Documentação Internacional Contemporânea (BDIC) de Nanterre, os Arquivos Nacionais e Departamentais realizaram um imenso trabalho de coleta, de classificação e de abertura de fundos que lançou luz sobre centenas de focos de luta até então não documentados.

Se o mês de maio de 68 foi, de início, o ponto de partida desses novos fundos, muito rapidamente o interesse foi estendido ao decênio 1965-1975. Também fora da França essa sedimentação ocorreu, com aquisições importantes, como por exemplo as do Instituto Internacional de História Social de Amsterdã. No caso de aspectos específicos, como as lutas homossexuais, a constituição de fundos inéditos sobre a história das comunidades no século XX permitiu arquivar um grande número de documentos dos movimentos da época, a começar 
pela Frente Homossexual de Ação Revolucionária (FHAR), e assim suscitar trabalhos até então inexistentes. A desativação de alguns grandes conglomerados industriais (indústrias automobilísticas, têxteis, siderúrgicas) ${ }^{4}$ nos últimos 20 anos propiciou igualmente um precioso trabalho de coleta sobre a vida dos trabalhadores nesses lugares e sobre as diversas lutas que aí se travaram. Um trabalho de memória coletiva que oferece ao historiador a possibilidade de se aprofundar até o nível local de uma fábrica ou mesmo de uma unidade dentro dela. Convém, enfim, lembrar a importância nessa área do Centro dos Arquivos do Mundo do Trabalho, criado em 1993 em Roubaix, ${ }^{5}$ ou, na área da história intelectual, o papel do Instituto Memória da Edição Contemporânea (IMEC), ${ }^{6}$ que, graças principalmente aos arquivos das revistas, permite acompanhar mais de perto suas vidas e seus engajamentos. ${ }^{7}$

Graças a essa renovação das fontes, vimos aparecerem progressivamente outros lugares da história de 68. Esses outros lugares em direção aos quais os meses de maio-junho se deslocaram estavam até então silenciados, de tal forma os acontecimentos haviam sido restringidos à narrativa das manifestações e das barricadas do Quartier Latin em Paris. Esses novos lugares são as fábricas - lembremos aquelas que entraram em greve em Besançon, no leste da França, e principalmente a da Rhodiaceta, grevista desde 1967 e palco, no início de 1970, do célebre conflito Lip. ${ }^{8}$ Mas outros lugares, como os quartéis, as prisões, os hospitais, também se puseram em movimento, agitaram-se, como se dizia então. Essa cartografia dos focos de luta põe em destaque o interior do país, e descobrimos assim uma outra França de 68, com centros como Lyon, Saint-Nazaire, Toulouse, Nantes... ${ }^{9}$ Esses outros lugares não se restringem, contudo, à França, pois o que acontecia fora dela repercutiu o tempo todo sobre o maio francês, a começar pela Guerra do Vietnã. Não existe, assim, um maio de 68 parisiense que se teria irradiado pelo mundo. Ao contrário, o que há é uma série de acontecimentos que tiveram uma recepção francesa desigual, mas que existiram cada um como um acontecimento autônomo.

Os "anos" 68 foram o momento de emergência de acontecimentos que ocorreram numa inédita contemporaneidade: num mesmo dia fizeram-se manifestações contra a Guerra do Vietnã em Washington e em Paris, e foram as mesmas imagens de sacos plásticos pretos que foram difundidas na França e em outras partes do mundo.

Mas o que me interessa também na torrente biográfica sobre Foucault é o desconhecido que Blanchot pensou ser o filósofo: o desconhecido do pátio da Sorbonne. Quem era aquele desconhecido? Afinal, seria tão importante saber quem era ele? A condição de anônimo não é ainda mais importante? Não foi esse o acontecimento para a história em 1968, a luz lançada sobre o anônimo como ator da narrativa histórica? 
Foi esse o sentido da galeria de retratos, dos retratos tremidos que tracei em 68: une histoire collective (ver boxe). A idéia era fazer um esboço daquelas silhuetas e lhes dar um lugar na paisagem que estávamos tentando compor. Pois, como sublinha Michel de Certeau (1968), naquele momento ocorreu um questionamento da ordem da fala. ${ }^{10}$ Dali em diante passou a circular uma nova fala e, sobretudo, emergiram novos locutores. Esse surgimento de um outro sujeito da história, o desconhecido do pátio da Sorbonne, que ora é uma mulher, ora um imigrante, um prisioneiro, um homossexual, um jovem secundarista, um malalojado, parece ter tido efeitos consideráveis sobre a disciplina histórica francesa. Fazer a história dos "anos" 68 é fazer a história da história que cada um de nós pratica.
Amor
Naquele dia de 1972, ele não se levantou como de costume para assumir seu posto. Em vez disso, ao sair do barracão insalubre onde dormia, juntou-se aos outros representantes sindicais para ir ao escritório entregar à direção o caderno onde haviam redigido suas reivindicações. Ele era tunisiano, mas havia ali também dois marroquinos e dois argelinos. Todos tinham participado da redação do texto, e naquele dia estavam começando uma greve, junto com os 105 operários da Pennaroya Gerland em Lyon.
Amor trabalhava na empresa desde sua chegada à França em 1969, depois do fechamento da mina da Pennaroya na Tunísia. Um engenheiro francês lhe havia dado uma carta de recomendação, dizendo que ele era um bom operário, que sabia falar e escrever francês. Sem documentos, primeiro fora recusado pela direção, mas depois fora contratado, e rapidamente chegaram seus papéis.
Por menos de 1000 francos, ele trabalhava 49 horas por semana; o trabalho consistia essencialmente em extrair o chumbo de baterias de automóveis descartadas e fundir o minério recuperado; o calor dos fornos era considerável, e não era raro alguém se queimar; as refeições eram feitas em meio a uma poeira carregada de chumbo extremamente tóxica; Amor e os outros operários moravam no local de trabalho, num dormitório coletivo, um barracão Algeco cheio de vazamentos. Os operários tinham o sono perturbado por aqueles que pegavam no serviço, e muitas vezes, quando um companheiro ficava doente ou estava ausente, emendavam dois turnos de oito horas. Certamente, quando chegou, Amor achou as condições de trabalho menos terríveis que as da mina tunisiana. Mas, conversando com os outros operários, ele progressivamente tomou consciência dos perigos que corria em Gerland. Uma série de relatórios do fiscal do trabalho já havia chamado a atenção da direção da Sociedade Mineradora e Metalúrgica de de Pennaroya instalada em Gerland, Lyon, para os perigos do saturnismo e para o estado deplorável dos barracões onde estavam alojados os 


\begin{abstract}
operários imigrantes e das instalações sanitárias: privadas sem portas, chuveiros sujos, em número insuficiente e distribuídos de modo desigual conforme os operários fossem "europeus" ou "imigrantes": na oficina do Alumínio, 2 chuveiros para 30 imigrantes, 3 para 6 europeus; na oficina do Chumbo, 12 para 45 imigrantes, 2 para 6 europeus; na oficina do Bronze, 3 para 27 imigrantes, 2 para 6 europeus: os números e as categorias eram da direção da empresa, que justificava, pelo número total de chuveiros, seu respeito aos regulamentos. A direção não tinha reagido; quando, em 19 de dezembro de 1971, um deles, Salem, sofreu um acidente mortal no trabalho, devido a uma máquina defeituosa, Amor e os outros operários imigrantes entregaram uma primeira lista de reivindicações em 27 de dezembro, e uma segunda em 25 de janeiro de 1972. Mas nada aconteceu. Assim, coletivamente, pouco a pouco emergiu a idéia de uma greve. Antes mesmo do início da greve formou-se um comitê de apoio, do qual faziam parte biólogos, médicos e juristas e numerosos militantes locais dos Cahiers de Mai. Foi por intermédio deles que Amor e os grevistas enviaram às outras fábricas da Pennaroya cassetes e cartas abertas em que expunham suas reivindicações. No segundo dia de greve, Amor teve a feliz surpresa da visita dos Trabalhadores Agrícolas de Rhône-Alpes que vinham trazer víveres. Amor, que pertencia à seção CFDT recém-criada, defendia o princípio das práticas coletivas: decisões em assembléia geral, eleição dos delegados oficina por oficina. Chegou a ser feito um filme sobre a greve no qual Amor explicava longamente os passos dados. O filme tornou-se uma arma a serviço dos grevistas; foi projetado por toda a França para explicar suas reivindicações; coletas foram feitas em quase toda parte. No fim da greve, em 11 de março, quase todas as reivindicações tinham sido atendidas.
\end{abstract}

Os "anos" 68 são para a história e as ciências sociais um momento de virada. Em meados de 68, os historiadores Jean Maitron, Michelle e Jean-Claude Perrot, e Madeleine Rebeyrioux, então professores universitários, publicaram um número da revista Le Mouvement Social composto de um conjunto de documentos coletados durante o mês de maio na universidade parisiense ocupada, que intitularam "A Sorbonne por ela própria". Eles aplicaram as regras usuais da profissão para constituir um corpus; restringiram a coleta, como deve ser feito, a um lugar e a um período determinados; definiram um método de classificação e de apresentação rigoroso para cada documento de arquivo. "A idéia de fazer essa coletânea de documentos nasceu", escreveram os cinco historiadores, "da nossa vida quotidiana naquele fim de primavera, em suma, da nossa experiência." $\mathrm{O}$ efeito 68 sobre as ciências sociais está sem dúvida contido nessa frase, nessa declaração tão simples quanto absolutamente singular: o encontro da história com a vida. 
Alguns historiadores levaram ao extremo essa experiência, sobretudo no Fórum de História da universidade parisiense multidisciplinar de Jussieu, surgida depois de maio-junho de 1968, ou na revista Le Peuple Français, criada por um membro do comitê de ação do Departamento de História de 1967-1969 da Faculdade de Nanterre. O especialista em China Jean Chesneaux (1922-2007) foi um dos artífices do engajamento desses historiadores radicais: era preciso, como ele teorizou alguns anos depois, "encorajar aqueles que participam de todas as lutas, operários ou ecologistas, mulheres ou occitanos, a romper com os automatismos do saber histórico dominante. Cabia-lhes construir eles mesmos sua relação com o passado, com base, é claro, nas aquisições comuns, mas apoiando-se igualmente em sua experiência própria" (Chesnaux, 1976).

Subitamente, portanto, durante aquelas semanas de maio, parece ter surgido uma possibilidade inédita de articular o saber e a existência. Essa articulação teve como conseqüência uma reformulação importante das ciências sociais, de que são testemunhos, a seu modo, os trabalhos célebres de Michel Foucault, Henri Lefebvre, Michel de Certeau e alguns outros, mas que também é sensível no quotidiano da pesquisa, nesse imenso oceano de produções do conhecimento, tão anônimo quanto essencial, que é a universidade. Pois ela atingiu ao mesmo tempo as fontes desses saberes, suas modalidades de investigação, suas escritas, mas também sua difusão e sua relação quotidiana com a sociedade. A história, a sociologia, a antropologia foram assim reinventadas um século depois de seu nascimento no fim do século XIX. Esses saberes, tão fortemente marcados no pós-guerra pelo pensamento marxista ortodoxo, desvencilharam-se progressivamente desse domínio, sem abandonar sua ambição crítica.

Em dezembro de 1968, o etnólogo e escritor Michel Leiris tinha quase 67 anos e foi o "curador selvagem", ao lado de Jacqueline Delange, de uma exposição no saguão do Museu do Homem, em Paris, intitulada Passages à l'âge d'homme, "ecoando a ação contestadora que eclodiu nas ruas na última primavera". A exposição foi desmontada ao fim de três semanas, diante da hostilidade da direção do museu, que a considerou subversiva; Leiris e Delange questionavam os caminhos que conduziam à idade adulta, "à maturidade" em nossas sociedades. "Uma de minhas tarefas tinha sido compor [...] uma vitrine que, em sua língua de uma retórica não discursiva [...], mostrasse que as maneiras de vestir os jovens e de engrená-los na vida da sociedade, pela iniciação ritual ou pelo ensino escolar, podem resultar em fracassos ou esbarrar em recusas" (Leiris, 1976: 198). E Leiris fez entrar no museu o assassino-poeta PierreFrançois Lacenaire, Arthur Rimbaud, Antonin Artaud, o dadaísta Jacques Rigaut e alguns outros suicidados da sociedade. Sem dúvida este foi o seu erro: 
não mais dirigir o olhar do etnólogo para as sociedades tradicionais, sobretudo africanas, mas voltá-lo para a sociedade a que pertencia e construir uma genealogia das diferentes formas de resistência da juventude à ordem estabelecida. Era essa nova relação de Leiris com seu objeto que estava em questão, assim como seu objetivo: produzir um saber do presente, um saber para o presente. Encontramos em muitos outros lugares esse mesmo gesto; o especialista em Antiguidade grega Pierre Vidal-Naquet age da mesma forma quando escreve com Alain Schnapp Le journal de la commune étudiante (1968) e tenta "produzir sobre o espaço contemporâneo análises do tipo daquelas que fiz a propósito da tragédia" (Vidal-Naquet, 2001). Na época da Guerra da Argélia um uso semelhante dos métodos científicos já havia sido feito - por exemplo, na investigação sobre o desaparecimento do matemático Maurice Audin (Vidal-Naquet, 1958), mas agora a idéia era pôr o saber a serviço da luta contra o colonialismo e seus crimes. Depois de 68, não se tratava mais de um projeto paralelo, e sim da preocupação de colocar a atualidade no centro dos saberes.

Essa mudança de ponto de vista foi acompanhada de uma renovação considerável das fontes. Sem dúvida, foi só dez anos depois daquela primavera agitada que o Parlamento Francês aprovou a Lei de Arquivos (Lei n ${ }^{\circ} 79-18$ de 3 de janeiro de 1979), que pela primeira vez dotou a França de uma verdadeira regulamentação para a conservação e consulta dos materiais para a história. Certamente, a Ecole des Chartes não foi em 1968 um lugar importante da contestação, mas a adoção dessa lei apresentada por um grupo de arquivistas contribuiu para produzir, entre os profissionais da memória, sua primavera. Essa mudança de ponto de vista se explica sobretudo porque, em maio, uma palavra singular, a dos operários e operárias, se fez ouvir, porque as lutas travadas levaram inúmeros estudantes a tomar consciência de que os intelectuais não eram os únicos a ter um discurso, e que aqui e ali se elaboravam coisas, circulava um pensamento. A memória operária tornou-se assim objeto de um interesse novo, como demonstram as coleções editoriais; mas, mais ainda, foi o discurso do marginal, do homem comum, como dizia o pintor e teórico da arte bruta Jean Dubuffet, que se tornou central nas ciências sociais. Prestar ouvido aos murmúrios do louco, do criminoso, do dominado tornou-se um imperativo da pesquisa compartilhado por muitos.

Os anos 70 assistiram assim a uma formidável valorização desses discursos desviantes que, aos olhos de todos então, diziam mais que qualquer outra fonte sobre a sociedade que procuravam estudar. $\mathrm{O}$ menor tornou-se o modo dominante da pesquisa, à maneira dos dossiês de arquivos que um Michel Foucault revelou: a autobiografia de um parricida (Pierre Rivière, 1973), as lembranças de um hermafrodita (1978) ou ainda as vidas de homens infames (1977) extraídas dos arquivos das prisões do Châtelet. Fora da França, tornou-se sensível um mo- 
vimento análogo com o desenvolvimento da micro-história, que pretendia reler a história a partir da análise da trajetória de um indivíduo dominado, que a disciplina histórica havia até então desprezado. Carlo Ginzburg foi um dos artífices dessa mudança do olhar operada a partir da documentação consultada. Os arquivos judiciários foram a porta de entrada no mundo desses seres menores ou desviantes. Afloraram acontecimentos minúsculos, até então silenciados pela narrativa acadêmica. A obra de Arlette Farge, Viore dans la rue à Paris au XVIII'̀me siècle (1979), assim como todos os volumes publicados na coleção "Arquivos", a que o livro pertence, é emblemática desse movimento. Na sociologia, como na antropologia, desenvolveu-se a análise de certas instituições - em especial o asilo - por meio de uma atenção infinita ao mínimo e ao corriqueiro a partir do discurso e dos atos dos principais interessados - os prisioneiros, os internos etc. Os sábios desceram de seu estrado para se misturar àqueles que desejavam estudar. Misturaram-se à multidão.

Esse mergulho levou alguns pesquisadores a mudar seu objeto de pesquisa. Foi o caso do sociólogo Alain Touraine, que no segundo semestre de 1968 publicou Le Mouvement de Mai ou le communisme utopique, primeiro ato de sua reorientação. Em 1970 ele fundou o Centro de Estudos dos Movimentos Sociais, decidindo que dali em diante seu trabalho consistiria na análise dos movimentos sociais como catalisadores da história contemporânea. Em 1973, publicou Vie et mort du Chili populaire: journal sociologique juillet-septembre 1973, e quase dez anos e dezenas de artigos depois, junto com F. Dubet, J. Strzelecki e M. Wieviorka, lançou Solidarité, sobre a situação polonesa. Na França, com sua equipe, demonstrou um interesse duradouro por várias lutas contemporâneas, como se, a seu ver, somente através delas fosse possível uma análise social. O sociólogo deveria desempenhar um papel crucial junto aos atores sociais. Touraine prega o desenvolvimento de pesquisas-ações-intervenções que devem no fim permitir aos militantes analisar eles mesmos o que está acontecendo, dispensando o sociólogo. Ao longo desses movimentos alguma coisa de essencial se enunciaria.

Essa atenção ao mundo social contemporâneo é exemplar no caso da historiadora Michelle Perrot, que em seu doutorado de Estado trabalhou com a greve operária no século XIX. "A greve era um meio de ouvir aqueles que nunca se ouve [...] Quando se trabalha, não se fala; com a greve, os operários saíam das fábricas [...] e criava-se ao mesmo tempo um espaço de fala." Essa preocupação com a fala dos dominados a encorajou em seguida, no início dos anos 70, a se interessar pela história da justiça e a abrir a grande oficina historiográfica das prisões, para, no fim da década, tornar-se uma das grandes iniciadoras da história das mulheres. Do proletário às mulheres, passando pelos presos da justiça co- 
mum, Michelle Perrot desenha de maneira quase emblemática essa mutação em direção à sombra da história .

Muitas dessas personagens, homens e mulheres, não tinham nome, muito poucas haviam deixado vestígios, mas a história de repente lhes abria um lugar, os historiadores escreviam seu destino. Certamente 68 é uma história coletiva, e foi também desse teatro de sombras que a partir de então saíram figuras ainda mais silenciosas: a do homossexual, a do imigrante e a do colonizado. Deste aquém, uma história se faz ouvir... E o desconhecido não é ninguém senão ela: Clio - a nova Clio.

Notas

1. Ver, sobre essa informação biográfica, a cronologia estabelecida por Daniel

Defert para Dits et écrits de Foucault (vol. $1,1995)$, bem como a que é apresentada no site www.michel-foucault-archives.fr.

2. Os instantâneos de Gilles Caron foram assim erigidos em fotografias semi-oficiais; neglicenciaram-se outros pontos de vista, como o de Elie Kagan, que cobriu o conjunto dos acontecimentos.

3. Ver a obra Mémoires de 68. Guides des sources d'une histoire à faire (1993).

4. Ao longo dos anos 80 , a indústria automobilística, mas também os setores mineradores e a indústria de modo geral foram vítimas da crise econômica. Numerosas empresas despediram em massa e muitas foram obrigadas a fechar.

5. Ver as páginas do site dos Arquivos Nacionais dedicadas a esse centro: http://www.archivesnationales.culture. gouv.fr/camt/.

6. Ver o site: www.imec-archives.com/.

7. A história das revistas modificou consideravelmente a história das idéias; ver por exemplo os artigos publicados em La Revue des Revues (www.entrevues.org/).

8. Empresa familiar fabricante de relógios de pulso, entre 1972 e 1975 a fábrica foi objeto de um conflito qui levou o(a)s operário(a)s a ocupar as instalações e a produzir relógios em regime de autogestão. Essa luta se tornaria um símbolo no pós-68. Ver o filme Les Lip, l'imagination au pouvoir, de 2007, dirigido por Christian Rouaud.

9. Ver a esse respeito as análises de Michelle Zancarini-Fournel (2008).

10. Ver o filme de William Klein, Grand soir et petit matin, de 1978. 
Referências bibliográficas

ARTIÈRES, Philippe \& ZANCARINI-FOURNEL, Michelle (dir.). 2008. 68: une histoire collective [1962-1981]. Paris: La Découverte.

BLANCHOT, Maurice. 1986. Michel Foucault tel que je l'imagine. Montpellier: Fata Morgana.

CERTEAU, Michel de. 1968. La prise de parole. Paris: Seuil.

CHESNEAUX, Jean. 1976. Du passé faisons table rase? A propos de l'histoire et des historiens. Paris: Maspero.

FARGE, Arlette. 1979. Vivre dans la rue à Paris au XVIII ${ }^{\text {eme }}$ siècle. Paris: Gallimard.

FOUCAULT, Michel (ed.). 1973. Moi, Pierre Rivière, ayant égorgé ma mère, ma soeur et mon frère. Paris:

Gallimard-Julliard (Tradução bras. Eu, Pierre Rivière, que degolei minha mãe, minha irmã e meu irmão. Rio de Janeiro: Graal, 1977).

1977. La vie des hommes infâmes.

Les Cahiers du Chemin, $\mathrm{n}^{\circ} 29,15$ jan. p. 12-29. (Trad. port. A vida dos homens infames. In: $O$ que é um autor? Lisboa: Vega, 1992. p. 89-128).

1978. Herculine Barbin dite Alexine

$B$. Paris: Gallimard (Trad. bras.

Herculine Barbin: o diário de um hermafrodita. Rio de Janeiro: Francisco Alves, 1982).
1995. Dits et écrits: 1954-1988.

Ed. por Defert D., Ewald F. e Lagrange J. Paris: Gallimard. 4 vol. (Trad. bras. Ditos e escritos. Rio de Janeiro: Forense Universitária. 5 vol. temáticos).

LEIRIS, Michel Leiris. 1976. Frêle bruit. Paris: Gallimard.

Mémoires de 68. Guide des sources d'une histoire à faire. 1993. Préface de Michelle Perrot. Paris: Verdier.

TOURAINE, Alain. 1968. Le mouvement de Mai ou le communisme utopique. Paris: Seuil.

1973. Vie et mort du Chili populaire: journal sociologique, juillet-septembre 1973. Paris: Seuil.

, DUBET, F., STRZELECKI J. \& WIEVIORKA M. 1982. Solidarité. Paris: Fayard.

VIDAL-NAQUET, Pierre. 1958. L'affaire Audin. Paris: Minuit.

2001. La vérité de l'indicatif: entretien réalisé par Philippe Mangeot et Isabelle Saint-Saëns. Vacarme, n ${ }^{\circ} 17$.

\& SCHNAPP, Alain. 1968. Le journal de la commune étudiante. Paris: Seuil.

ZANCARINI-FOURNEL, Michelle. 2008. Le moment 68. Paris: Seuil (L'Univers Historique).

\section{Resumo}

1968 aconteceu não apenas na cena parisiense, mas em um conjunto de lugares que foi revelado pelo alargamento da noção de "fonte", ocorrido com o interesse por arquivos privados, a valorização de fundos esquecidos, a 
constituição de fundos específicos, a abertura de arquivos públicos. Essas cenas marginais revelam outros atores, os personagens anônimos dessa história. O surgimento da figura do anônimo colocou no centro da disciplina histórica, e de modo mais amplo, das ciências sociais, esses indivíduos sem rosto. Foi como se a História tivesse sido capturada pelo acontecimento, e um novo tipo de saber tivesse emergido com ele.

Palavras-chave: maio de 1968, fontes, arquivos pessoais, personagens históricos anônimos

\section{Abstract \\ 1968 took place not only in Paris, but in a number of other places that came to light thanks to the enlargement of the notion of "source" by the inclusion of personal archives, neglected or specific colletions, secret files. These marginal scenes bring in other actors, the anonymous characters of this story. The light thrown upon the anonymous has brought to the core of historical discipline, and of social sciences at large, these faceless individuals. Its was as if History had been captured by the event, and a new kind of knowledge had emerged with it.}

Key words: May 1968, sources, personal archives, anonymous historical actors

\section{Résumé}

1968 fait événement non pas seulement sur la scène parisienne, mais sur un ensemble de lieux révélé par l'élargissement de la notion de "source", qui a intégré les archives personnelles, le réinvestissement de fonds d'archives délaissés, la constitution de fonds spécifiques, l'ouverture avec dérogation des archives publiques. Ces scènes marginales donnent à voir d'autres acteurs, les personnages anonymes de cette histoire. Or, précisément, ce surgissement de la figure de l'anonyme a placé au centre de la discipline historique et plus généralement des sciences sociales ces individus sans visages. Tout s'est donc passé comme si l'Histoire avait été saisie par l'événement, et un nouveau type de savoir avait émergé avec lui.

Mots clés: Mai 68, sources, archives personnelles, acteurs anonymes de l'histoire 